\title{
Developing a Curriculum Framework for a Business Undergrad program
}

\author{
Hong Yuh Ching
}

\begin{abstract}
This article aims to report the experience of developing a curriculum framework, combining the use of constructivist approach with Design Thinking DT, in a university located in São Paulo region, Brazil. This research is theoretical-empirical with descriptive objective and the method used was action research. The qualitative comments from students reflect how learning became more meaningful and enjoyable and they are learning how to work collaboratively. This framework can provide coherence to the curriculum and will help faculty to deliver an interdisciplinary curriculum and students to navigate the competencies jungle that underpins the working environment. This is its contribution.
\end{abstract}

Index Terms-Business program, constructivist approach, curriculum framework, design thinking.

\section{INTRODUCTION}

The future, that's what we prepare students for, to be confident leaders with the knowledge and skills to effectively adapt to, and overcome, the challenges of an evolving global economy. With so much emphasis on what's next, it's imperative for business school curricula to focus on the future. In addition to preparing students, curriculum is an essential ingredient for high-quality business education. It reflects school's unique mission, encapsulating the intellectual capital and character of business school brand [1].

The technology-driven world in which we live is a world filled with promise but also challenges. The workforce transitions ahead will be enormous. Reference [2] estimates that as many as 375 million workers globally (14 percent of the global workforce) will likely need to transition to new occupational categories and learn new skills, in the event of rapid automation adoption.

The technology-driven world in which we live is a world filled with promise but also challenges. The workforce transitions ahead will be enormous. Reference [2] estimates that as many as 375 million workers globally (14 percent of the global workforce) will likely need to transition to new occupational categories and learn new skills, in the event of rapid automation adoption.

It is a fact that knowledge acquisition is still taught fragmented into isolated subjects or disciplines. Curriculum framework is not designed to help teachers execute a holistic and interdisciplinary learning. Reference [3] states that the dominant approach to business education is that knowledge should be compartmentalized into programs or disciplines; they are integrated into the core; and cores are combined into curricula. Business schools are organized into functional departments - accounting, marketing, strategy etc. under the assumption that business education can be best taught dividing in silos or areas of specialty. In this same line, [4] argue that business schools are not developing students' skills to adapt them to an increasingly complex and turbulent business environment. This leads to a negative classroom experience by the students as well as lack of a process to follow [5].

Business education has been subject to considerable scrutiny and although many higher education schools have adopted new pedagogical tools and active learning methods, the quality of education is still far from achieving significant efficiency. This was the cover story of the issue nov/dec 2013 of the magazine RBA
Revista Brasileira de Administração [Brazilian Magazine of Administration], published by the FCA Federal Council of Administration "We are the biggest program in Brazil in number of students, but how is the quality?"

There is evidently a gap between what the business schools are teaching and what the market needs [6]. This is referred by [7] as the global achievement gap, the gap between what the schools are teaching and testing versus the skills all students will need for careers, college and citizenship in the $21^{\text {st }}$ century".

The critical point is to get teachers and students motivated and equip them tools and methods to create positive classroom experience while exercising work with projects. Design Thinking (DT) can serve as such a format. DT has been defined as approaching management problems as a designer approaches design problem, with an open mind [8].

In a constructivist approach, the students will work in interdisciplinary projects linking facts and phenomena as opposed to breaking down a complex real life situation into little parts and isolated subjects or disciplines [5]. For these same authors, constructivism can be considered as dialogue between the learning theorists and instructional designers, but they claim that sometimes this does not happen and because of that, the curriculum is not designed as per the learners' needs. This is a strong reason why Design Thinking should be applied hand-in-hand with constructivist approach.

Reference [9] mapped some higher education business programs that include DT in their offerings to business and management students. They found out that DT has been used in product design for decades and more recently in system design and its application is not limited to large private sector companies, but also to small size companies and the public sector to find ways of developing solutions to complex problems. Reference [10] claim the need for Design Thinking in business schools. For them, it provides a much needed approach for dealing with complex, ill-defined problems. Reference [11] used DT in a learning situation project proposed to business students.

The articles researched are more focused in how DT is being taught to students in business schools around the world. However, to the best of the author's knowledge, no article was found using DT as a methodology to develop a curriculum framework. This is the novelty of this paper.

This article aims to report the experience of developing a curriculum framework, combining the use of constructivist approach with Design Thinking DT, in a university located in São Paulo region, Brazil. It brings to discussion some necessary didactic pedagogical developments as well as changes in the construction of competencies to the business program. This framework can provide coherence to the curriculum and will help faculty to deliver an interdisciplinary curriculum and students to navigate the competencies jungle that underpins the working environment. This is the contribution of this paper.

\section{LITERATURE REVIEW}

This section is divided in two parts. The first deals with the concept of constructivist approach while the second deals with DT, its meaning and phases. 


\section{A. Constructive Approach}

According to this approach, the students construct the knowledge assisted by the facilitator rather than receiving it from the professor/lecturer or reading from the textbook [12]. For [13] this approach forces the students to be an active member and engaged in the classroom as opposed to traditional teaching approach. In this same line, [14] states that students construct their knowledge together with the lecturer in his role of facilitator helping them in this task.

For [15], constructivism is an epistemological view of knowledge acquisition emphasizing knowledge construction rather than knowledge transmission and the recording of information conveyed by others. Learners must build their own understanding through an active construction process [16]. How information is presented and how learners are supported in the process of constructing knowledge are of major significance.

For [17], learning is a process of understanding which leads to modification in the behavior of the learner and according to constructivist theory, this is achieved through experience. Reference [5] used DT as a meta disciplinary methodology that offers teachers the needed support. Their study confirms an improvement in classroom experience for teacher and student alike when using DT.

\section{B. Design Thinking}

For [10], DT is an iterative, exploratory process involving visualizing, experimenting, creating and prototyping of models and gathering feedback. For [18], DT is a methodology that imbues the full spectrum of innovation activities with a human-centered design ethos. Reference [8] state that DT is the way designers think and it results from the nature of design work: a project based work flow around wicked problems.

Design Thinking has been identified as a new paradigm for dealing with problems in many professions, notably Information Technology [19]. In this same line, companies like Procter \& Gamble, Cirque du Soleil, RIM, and others use design thinking to push knowledge through the stages in ways that produce breakthrough innovations and competitive advantage [20].

Despite the different concepts of DT mentioned above, [21] believe that the ultimate goal of DT is to apply a creative, non-linear and interactive way of thinking and a process methodology for new ideas and to solve problems of business every day.

Reference [9] investigated design, design thinking in higher education business programs, and defined four distinct educational approaches around human centered innovation, integrative thinking, design management and design as strategy.

Reference [11] applied DT in classroom and concluded that helping the students to think like designers may prepare them to face challenges and to solve problems in school as well as in their professional lives.

Design Thinking process has five phases that help navigate the development from identifying a design challenge to finding and building a solution [22] and they are the following:

The problem definition and understanding (Discovery). It starts with understanding the challenge that will guide the questions and help stay on track throughout the process. The work continues with interviewing the personas, ie, the future users, consumers or customers and finishes gathering and documenting information with a curious mindset [22].

Observation (Interpretation). Begin to make sense of all the information and inspiration collected to identify themes or categories and make sense of the findings and define insights as inspiring opportunities [22].

Generating of ideas (Ideation). Take the time to set up appropriately in order to get the most out of this session. Then you are able to refine ideas by looking at what is most important about your idea and find ways to evolve and develop it further [22].

Prototyping (Experimentation). This phase brings idea to life. By building prototypes, you can share your idea with other people and refine it, if necessary. By making it visible and tangible, users can test it and provide useful feedback [22].
Testing and Optimization (Evolution). This phase is the development of the concept over time. Plan the next step and engage others onboard and create a timeline with your team for bringing the concept to life [22].

Important to say that DT is based on iteration and repeat a phase is not a waste of time and effort, it can be seen as construction of knowledge or gain of learning success.

\section{RESEARCH METHOD}

This research is theoretical-empirical with descriptive objective due to its objective. The approach adopted is qualitative and the procedure is a single case study, a university located in São Paulo region. The method used was action research because it aims to point out aspects from the author's perspective, since the author and the working group participated actively in all processes and their participation and intervention were paramount for its preparation. Their perspectives are empirical sources for explaining and documenting from the knowledge processes to practices regarding Design Thinking.

A permanent working group was formed by the author and six professors of the faculty. Other groups were formed on an ad hoc basis, like in the Empathy Map with five students and three former students, in the Interpretation phase with professionals from talent development consultancies, human resource and former students and, finally in the Ideation phase.

Qualitative analysis was used for processing and analyzing information obtained through external and internal documents, professors and students' feedback from focus-group sessions. These sessions occurred during the first half of 2018.

The author and his working group had an insight "what would be different if we think like designers". They wanted a tool that give them new way of thinking and innovating our curriculum.

Reference [23] described one reasoning pattern to solve problems or to create value for others called Abduction. The equation is:

$\begin{array}{lll}\text { WHAT } & \text { HOW leads to } & \text { VALUE } \\ \text { (thing) } & \text { (working principle) }\end{array}$

In this equation, [23] states that we know both the value we wish to create, and the how, a working principle that will help achieve the value we aim for. We work backwards, starting from the 'know' in the equation (the value) and then adopt or develop up a frame. This reasoning pattern was followed in designing the present curriculum framework.

Every design begins with a specific and intentional problem to address, this is called a design challenge [11]. Understand the problem is crucial and he designers should know what the client really wants. The value aspired is to have students better qualified, competency wise, to meet industry expectations. And the how is the framework to be designed.

The implementation process followed the same phases of Design Thinking: (1) discovery (2) interpretation; (3) ideation; (4) experimentation. The intensive process to design our framework occurred throughout 2018 and implemented in February 2019. Worth to mention that the author and some teachers of the working group had already some experience in applying DT in classroom.

\section{IMPLEMENTATION PROCESS}

The definition of the challenge was the first activity and for this purpose, the working group listed initially their motivations and tensions.

Motivations: rethink the triad teaching-learning-assessment and utilize what is already good; change the current educational model present in the business undergrad programs and develop competencies that will enable the students to work in a reality of constant changes.

Tensions: boring classes, lack of engagement of students and teachers in more participative classes, lack of students' vision of the way forward throughout the program and isolated disciplines. 
The definition of the challenge or problem was result of iterations and discussion between the members of the working group. This reinforces the solution based, iterative nature of the design process. For [10], this process may begin with some initial specification and the client does not know what he wants until he can see what he can get.

Challenge or problem defined in consensus: How can we develop the competencies demanded by the market in the students in a more collaborative way between the teachers and students?

In sequence, the group created specific descriptions of the persona they want to engage with, ie, picture the characteristics of persona they are looking for. It resulted in the following statement "student of night program of medium class, resident in the neighborhood of the school and mostly young. He/she joined the program with deficiencies in his/her learning, promising and still naïve. Throughout the semesters, he/she matures personal and professionally, becomes more critical, confident in the choice of the career and the school and concerned in getting a good job".

This group of professors also raised some guidelines that helped in solving the above challenge: how the students learn, instead of what learn is more important; the knowledge organized and interrelated is better taught than the knowledge specific and isolated; the apprentices must build knowledge rather than being transmitted.

\section{A. Phase 1: Discovery}

The Empathy Map was used for this purpose. This is a collaborative tool teams can use to gain a deeper insight into their personas. Two meetings were held, one with the working group and another one with five students and three former students. We asked them what the persona see, say and do, hear, think and feel? The participation and engagement of the students is a crucial characteristic of constructivist learning. This was true also in the next two phases of DT. Discovery is the phase where attention is given to user needs. As stated by [18], the empathy for users allows the designers to shift their point of view to better imagine solutions that meet the users' needs.

The working group felt overwhelmed by the amount of information generated by the Empathy Map. They used the hour immediately after the session to start capturing what they have learned. In search for meaning in the second step of DT Interpretation - the group began to make sense of all that information and inspiration.

\section{B: Phase 2: Interpretation}

They concentrated in cluster related information by grouping similar findings into categories or buckets and post-it the findings on a large sheet of paper and look for more evidences of the same theme. Information was regrouped and new versions of the headlines added until they feel strong.

Then, the two groups revisited the question that started the discussion: "how do our findings relate to our challenge?" In doing so, the information was narrowed down to those insights that were relevant and three clusters were taken off. The groups limited the insights to the most important and named the clusters in six headlines with their related findings (see figure 1).

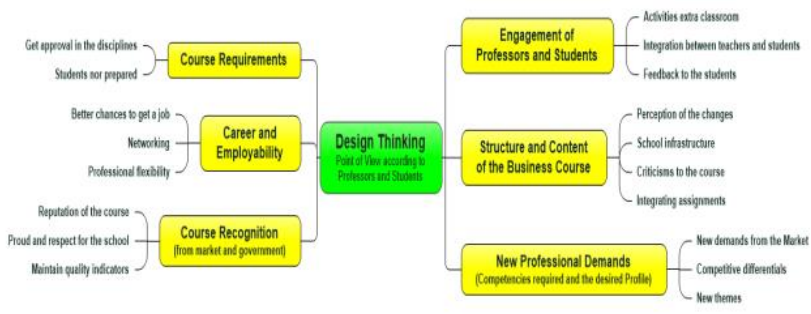

Fig. 1. Cluster related information.

The next part of the Interpretation phase was to look for links between headlines/clusters. The professors felt surprising by what they found because of the natural connections between the clusters and the proposed challenge. See figure 2 . The main headline/cluster is New Professional Demands that triggers the redesign of the
Structure and Content of the business program and have the teachers and students more engaged. These clusters will lead into a new Program requirements that will bring Program Recognition from market and government and ultimately to student employability and career.

At the end of this phase, a group of professionals from talent development consultancies, human resource and former students was invited to give an outside perspective and check on what was done so far. We were particularly concerned as to which clusters to pursue because of our limited resources and time constraint.

This group advised us to focus on what they considered the two most important clusters - new professional demands and structure and content of the program. They reckon that teachers and students will be more engaged and program requirements can be redesigned as consequence of a new structure and content. After a few years, recognition will come and this will improve our students' employability and careers. The other clusters were parked aside because of limited human resources and time constraint.

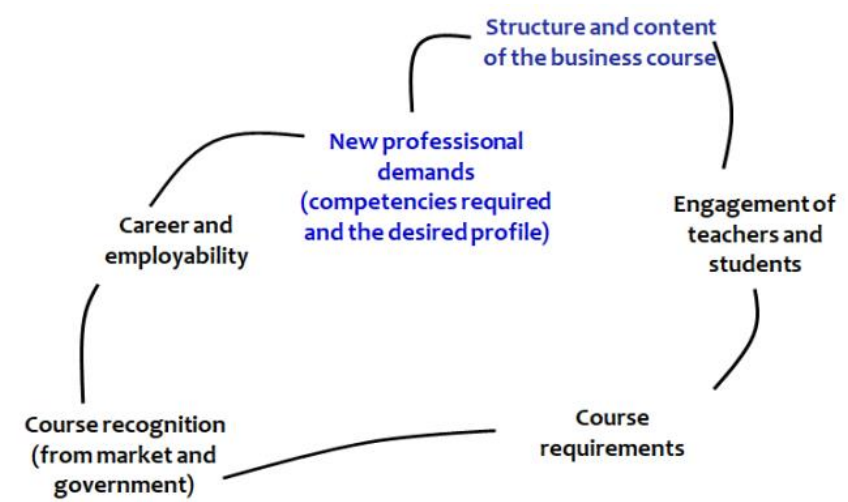

Fig. 2. Link between the clusters.

\section{C: Phase3: Ideation}

Ideation means generating lots of ideas and brainstorming encourages to think expansively and without constraints [22]. This time, a bigger number of professors, students and former students were invited to put them on a board. They were separated in two groups in two different days.

They concentrated in grouping similar ideas into categories or buckets and post-it the ideas on a large sheet of paper and look for more evidences of the same theme. Ideas were regrouped and new versions of the clusters added until they feel strong. Clusters were divided in Structure (S) and Content (C). The result can be seen on figure 3 .

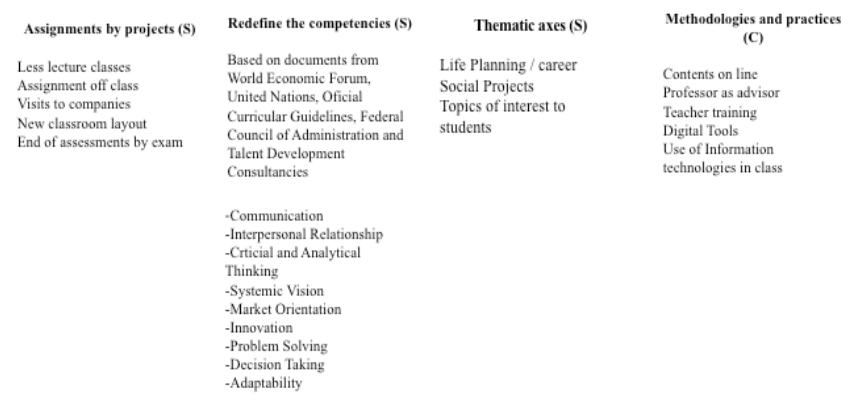

Fig. 3. Clusters divided in structure and content.

Initially this big group worked on one important cluster - new professional demands that is all about the competencies required from the professional in the near future. The group based on documents from [24], [2], [25], [26] and [27]. This latter displays fifteen core competencies divided in delivery related, interpersonal and strategic. The group came up with nine core competencies required in the professional environment: 
Communication; Interpersonal Relationship; Critical and Analytical Thinking; Systemic Vision; Market Orientation; Innovation; Problem Solving; Decision Taking and Adaptability Some of the above nine competencies appear in most of the documents consulted like Critical and Analytical Thinking, Innovation, Problem Solving and Decision Taking and they will be also critical in this new technology-driven world we are embarking. Regardless of which competencies chosen, all students will need to build them for their careers, college and citizenship in the $21 \mathrm{st}$ century.

\section{D: Phase 4: Experimentation}

This phase brings ideas to life. Building prototypes means making ideas tangible, learning while building them and sharing them with other people [22]. Generating prototypes also serves a key role in the design process. Flowcharts, graphs, sketches and prototypes clarify the characteristics of the idea and make it more amenable to critical considerations and feedback [10].

The working group came up with two different versions of how to frame the second important cluster - structure and content of the program. The members decided to get feedback from the same participants that helped in the Ideation phase. The following prompts were used to heat the discussion: What got them excited? Which parts would participants like to improve? What did not work? What needs further investigation?

The pedagogical proposal of this Business program transcends the contents and disciplines. It configures a teaching-learning ecosystem in which the actions, activities, structure and methodologies favor the development of the students. It is strategic, therefore, that the learning activities should focus to the development of competencies and their assessment. There is need of intense use of active methodologies and expose the students to a proactive stance.

Having this in mind, a curricular structure of the program was initially designed (see figure 4). It was consensus that the students should have a clear view of their formative itinerary and this is represented by thematic axis in each year of the program as shown below:

1st year: Know the organizations internal and external environment and your role in the society

2nd year: The organizations and the relations with their stakeholders

3rd year: Transforming projects in business

4rth year: Integrating and expanding business

Thematic Axes in each year

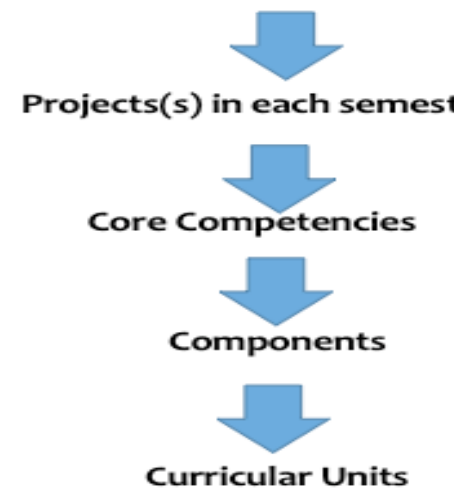

Fig.4. Curricular structure.

Next, for each thematic axis, major projects will be worked out per semester. See figure 5 .

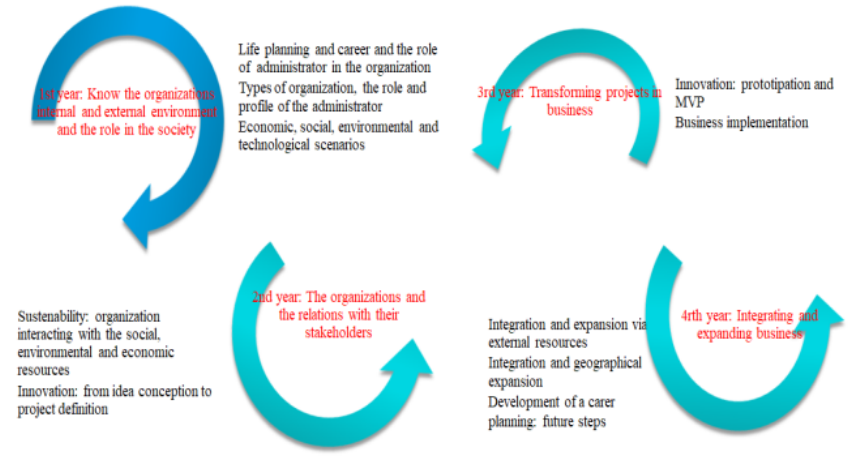

Fig.5. Thematic axes and respective major projects.

The next stage of the curriculum framework was the development of core competencies along the thematic axes and their respective major projects. It can be seen in chart 1 . This chart provides the students with a clear roadmap of the destination and how to reach it. The competencies were arranged in an appropriate sequence for the student's learning as he progressed along the program. Nevertheless, several barriers can be expected to adopting competency-based model in curriculum design. Reference [28] listed three of them: measurability (use of criterion referenced, measurable assessment methods); resistance (poor designed assessment methods can induce negative impression) and time-consumption to build the architecture for a competency-based model.

The major projects in each semester were then broken down into components (micro projects) so that they can developed by students in the classroom. The components are related to each major project and aligned with its objective. They will origin the curricular units in each semester that will provide the conceptual contents to support the components. Design Thinking should ultimately emphasize project-based learning and working in teams and this is the cornerstone of this framework. For purpose of illustration, the major projects, respective objectives and components for the first year of the program are illustrated in figure 6 . 
Chart 1: Formative itinerary and its competencies

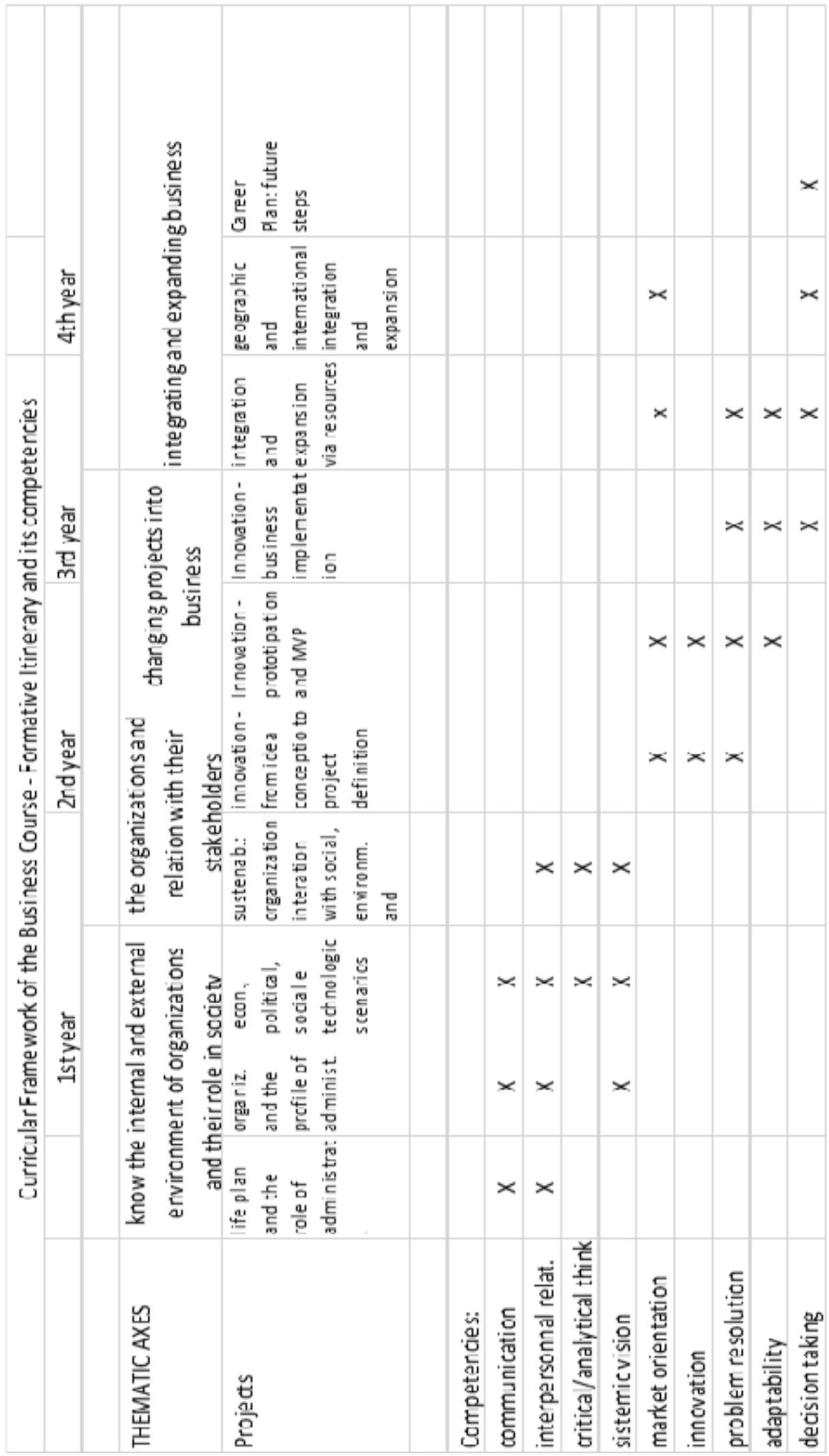




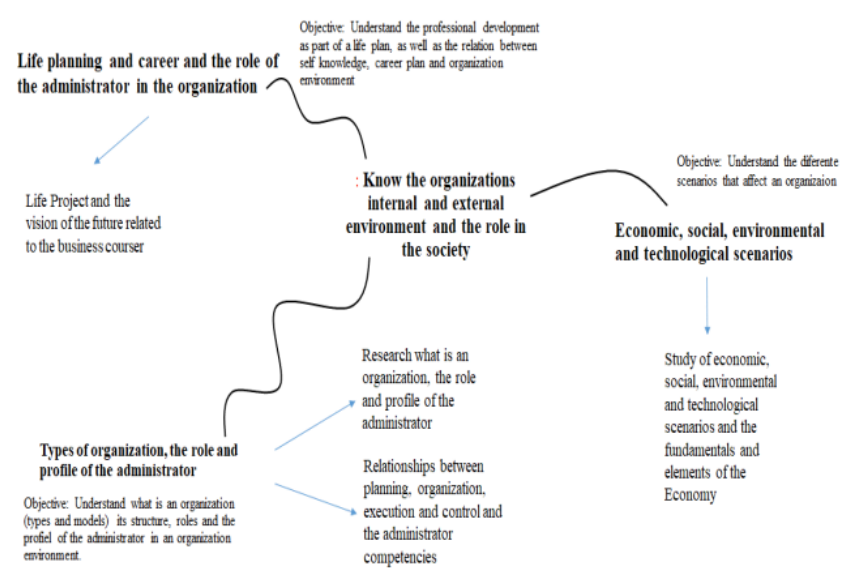

Fig.6. Major projects, respective objectives and components for the first year of the program

The figure 7 displays the links between the components in the student's journey throughout the business program showing the cause-effect relations.

Finally, the curricular units in each semester were elaborated in order to support the components considering the flexibility, the interdisciplinarity and articulation of the theory with the practice. For the sake of space, the curricular units will not be shown in this paper.

In order to introduce the curriculum framework, the working group was concerned of how to empower the newcomer students and the faculty in this new framework. For the faculty, sensitize them in working in the form of projects (constructivist environment) to ultimately assist the students to build the competencies. For the students, in this project work environment, how to build and utilize the competencies in each scenario of change?

Two sessions were prepared, one for the faculty a week before the classes started with the duration of four nights of 4 hours in each night. The other session was dedicated to the students in the first week of classes in a blended form in two alternated nights.

\section{RESULTS}

DT projects focus on constructivist learning and integrate content so the students can link facts and phenomena. Encountering new contents and interrelations of information, solving teams crisis and getting feedback are difficult aspects of a project learning, but also crucial for developing competencies

The results are still in the preliminary stage because of the small number of freshmen students and teachers that interacted with this curriculum. Focus group sessions took place during March/April 2019 to assess the freshmen' and professors' perceptions related the new curriculum framework. The key outcomes from these sessions were positive. All of them said that this has been a novel experience of teaching-learning and this forces them to change their mindsets. The students felt more engaged in the classes, they were able to interrelate information and integrate contents that made sense to them. The teachers clearly saw improvements in the students' performance and engagement. They felt a little uncomfortable in assuming a mentor approach rather than a content transmitter. In the constructivist approach, the role of the teacher is being a facilitator providing guidance, encouraging the students and facilitating their work [29].

The qualitative comments from students also reflect how learning became more meaningful and enjoyable, they are learning how to work collaboratively and more engaged with their colleagues and teachers.

As far as the student competence development is concerned, the teachers got positive feedback from the students and this early stage success leads to motivation of both students and teachers in realizing more constructivist learning.

\section{WHAT HAS BEEN LEARNED AND FINAL CONSIDERATIONS}

Looking back to what was done, we can comment on the concerns, actions and make some criticisms. In the first phase when the Empathy Map was being elaborated, we should have visited analogous settings (other business programs) and their faculty and students to collect their views.

In the second phase, of Interpretation, we reckon that the second group formed by professionals from talent development consultancies, human resource and former students was a good move. They provided an outside perspective and advised us to focus on what they considered the two most important clusters.

The third stage, of Ideation, can be problematic if not managed properly. So much time can be consumed in this phase with no corresponding value in the ideas proposed. A suggestion is to have a neutral person conducting the brainstorm sessions and following the brainstorm rules - defer judgment, encourage wild ideas, build on the ideas of others, one conversation at a time, be visual and go for quantity [22].

As mentioned in the fourth phase, Experimentation, the working group came up with two different versions of how to frame the second important cluster. To get to these two versions, the members were instructed to build the prototypes visually, i.e., drawings, flowcharts, infographics and storyboards. This was the most fun phase of DT. And the feedback from people that were not involved in prototyping is very critical.

Revisiting the three barriers mentioned by [28], this business program has already in place criteria measurable assessment methods, using Bloom's taxonomy [30]. This addresses the resistance barrier because the present design methods give positive impression. Notwithstanding, the author and the working group feel that resistance issue may come from some teachers of the faculty, more accustomed to be a content transmitter, that were not yet exposed to this curriculum. As mentioned before, the session of four nights/sixteen hours is designed the break this resistance.

Finally, the third barrier is a reality. It requires a lot of time and effort to build learning objectives, experiences and instructional activities. The strategy is to build them one semester in advance and one at the time (now, working with the architecture for the second half of 2019), so we can design and improve with the feedbacks received.

In a constructivism approach, conceptual change is the key to student's cognitive growth and development and, at same time, becomes an essential quest for the teacher's professional action. For [31], it is fundamental for the development of the student's cognitive growth the delineation of the methodological strategies to be adopted in the classroom.

This implementation has produced useful insights as well as its application and potential benefits. It would be interesting to monitor this implementation further and to report the findings in a future study. Ultimately, the goal is for undergrad students to enter employment better qualified to meet industry expectations. The limitation of this study was the short time that students and former students had to devote to the discussions because most of them work during the daytime 


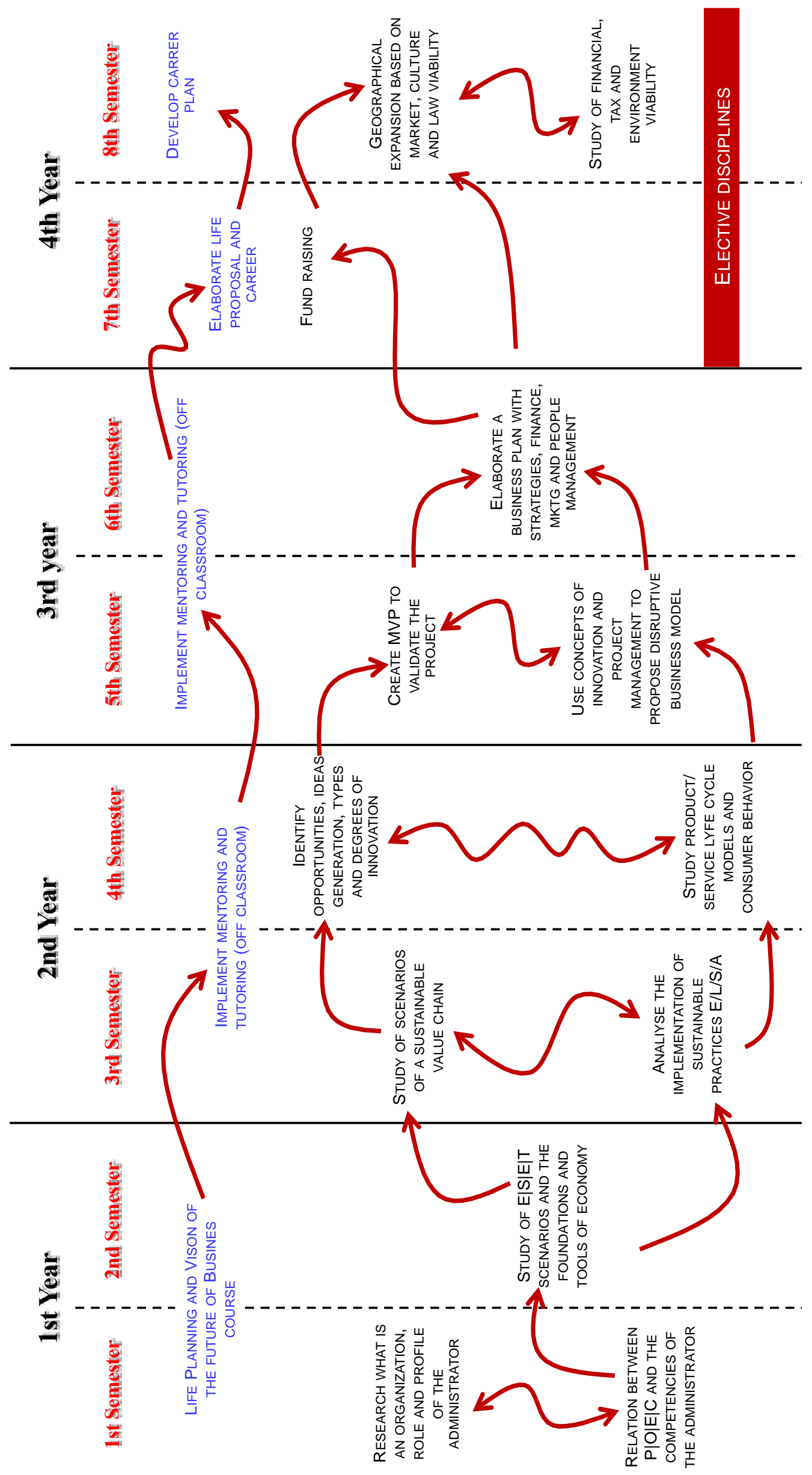

Fig.7. Links between the components. 


\section{REFERENCES}

[1] K. B. Walker and E. L. Black. Reengineering the undergraduate business core curriculum: aligning business schools with business for improved performance. Business Process Management Journal, vol. 6 (3), pp. 194-213, 2000.

[2] McKinsey \& Company. Jobs lost, jobs gained: workforce transitions in a time of automation. 2017. Available: file:///Z:/Praticas\%20de\%20Inovação/MGI-Jobs-Lost-Jobs-GainedExecutive-summary-December-6-2017.pdf

[3] C. Nelson. Harvard's hollow core. The Atlantic monthly, September, 70-80, 1990.

[4] S. Waddack and J. M. Lozano. Developing more holistic management education: lessons learned from two programs. Academy of Management Learning \& Education, vol. 12, pp. 285-294, 2015.

[5] A. Scheer, C. Noweski and C. Meinel. Transforrming constructive learning into action: design thinking in education. Design and Technology Education: An International Journal, vol.17 (3), pp. 8-19, 2012.

[6] Federal Council of Administration FCA. Letter $\mathrm{n}^{\circ}$ 109/2014/CFA/CFP, 2014.

[7] T. Wagner. The Global achievement gap: why even our best schools don't teach the new survival skills our children need and what we can do about it. New York: Basic Books, 2010.

[8] Dunne and R. Martin. Design thinking and how it will change management education: an interview and discussion. Academy of Management Learning \& Education, vol. 5 (4), pp. 412-523, 2006.

[9] J. H. Matthews and C. Wrigley. Design and design thinking in business and management education and development. In $25^{\text {th }}$ Annual Australian and New Zealand Academy of Management Conference, Wellington, New Zealand, 2011.

[10] R. Glen, C. Suciu and C. Baughn. The need for design thinking in business schools. Academy of Management Learning \& Education, vol. 18 (4), pp. 653-687, 2014.

[11] H. Y. Ching. Design thinking in classroom: an experience with undergrad students of a business program. Business and Management Research, vol. 3 (2), pp. 110-119, 2014.

[12] E. B. Cohen. A philosophy of informing science. Informing Science: the International Journal of an Emerging Transdicipline, vol. 12, 1-15, 2009.

[13] J. S. Kim. The effects of a constructivist teaching approach in student academic achievement, self-concept and learning strategies. Asia Pacific Education Review, vol. 6 (10), pp. 7-19, 2005.

[14] R. J. Draper. School mathematics reform, constructivism and literacy: a case for literacy instruction in the reform-oriented math classroom. Journal of Adolescent \& Adult Literacy, vol. 45 (6), pp. 520-529, 2002.

[15] J. M., Applefield, R. Huber and M. Moallem, Constructivism in theory and practice: toward a better understanding. The High School Journal, vol. 84 (2), pp. 35-59, 2000.

[16] A. L. Brown. The advancement of leaning. Educational Researcher, vol. 23, pp. 4-12, 2004.

[17] H. Gardner. Five minds for the future. Harvard Business School Press, 2007.

[18] T. Brown. Design thinking. Harvard Business Review, vol. 86, pp. 8492, 2008.

[19] F. P. Brooks. The design of design: essays from a computer scientist. NJ: Addison-Wesley Professional, 2010.
[20] R. Martin. The Design of business. Cambridge MA: Harvard Business School Press, 2009.

[21] C. Dym, A. M. Agogino, O. Eris, D. D. Frey and I. J. Leifer. Engineering design thinking, teaching and learning. Journal of Engineering Education. January, pp. 103-120, 2005

[22] IDEO. Design thinking for educators, 2nd edition. 2012. Available: http://www.designthinkingforeducators.com.

[23] K. Dorst. The core of design thinking and its application. Design Studies, vol. 32, pp. 521-532, 2011

[24] World Economic Forum. The future of jobs report. 2018. Available: file:///Z:/Praticas\%20de\%20Inovação/WEF_Future of Jobs_2018.pd $\underline{\mathrm{f}}$

[25] National Council of Education CNE (2005). Official curriculum guidelines. Resolution $\mathrm{n}^{\circ} 4$ de 13/07/2005. Brasília, 2005. Available: $<$ http://

www.udesc.br/arquivos/id_submenu/83/resolucao_2005_4_cne_ces.p df>.

[26] Federal Council of Administration FCA.National research system CFA/CRAs [Pesquisa Nacional. Sistema CFA/CRAs], 2015.

[27] OECD (2014). Competency framework. Available: https://www.oecd.org/careers/competency_framework_en.pdf

[28] S. Y. Chyung, D. Stepich and D. Cox. Building a competency-based curriculum architecture to educate $21^{\text {st }}$-century business practitioners Journal of Education for Business, vol. 81 (6), pp. 307-311, 2006.

[29] C. Wirfelt. Educational multimedia and teachers' needs for new competencies: a study of compulsory school teachers' needs for competence to use educational multimedia. Educational Media International, vol. 37 (4), pp. 235-241, 2000.

[30] H. Y. Ching, and E. C. da Silva. The use of Bloom's taxonomy to develop competences in students of a business undergrad course. Journal of International Business Education, vol. 12, pp. 107-126. 2017.

[31] V. F. Oliveira and Z. Chamberlain. (org.) Engineering without borders [Engenharia sem fronteiras] Passo Fundo: Ed. Universidade do Passo Fundo, 2011.

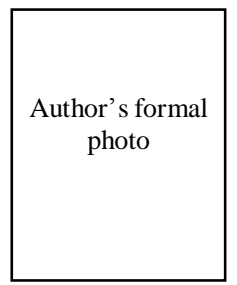

Born in Hong Kong on $1^{\text {st }}$ April, 1953. Bachelor degree in Business at Getulio Vargas Foundation, $S$ Paulo, Brazil, Master of Science in Accounting at PUC/SP and Doctor degree in Engineering at Unicamp, SP, Brazil. Major fields of study are in business education, finance and sustainability.

He has worked in corporate positions for over 20 years, has consultancy experience for 10 years and since 2010 is Head of Business Department at Centro Universitario FEI located in São Paulo State, Brazil. He has written seven books and published over 25 articles in local and international journals.

Dr Ching is a member of the Regional Board of Administration of S Paulo State. He received in 2019 a Reviewer Certificate of Journal from Corporate Accounting \& Finance and in 2018 Certificate of outstanding contribution in Reviewing from Journal of Cleaner Production. 